\title{
PERANCANGAN PROTOTYPE INTERFACE SISTEM INFORMASI KEBERADAAN DOSEN
}

\author{
M. Irfan ${ }^{1)}$, Evi Dwi W'), Dharma S. ${ }^{3)}$, Dini Saputri ${ }^{4)}$ \\ 1,2,3,4) Teknik Informatika, Universitas Muhammadiyah Malang \\ Jl. Raya Tlogomas 246 Malang \\ Email :irfan@umm.ac.id ${ }^{1)}$,evidwi@umm.ac.id ${ }^{2}$,dharma@umm.ac.id ${ }^{3)}$,dini@umm.ac.id ${ }^{4}$
}

\begin{abstract}
Abstrak
Teknik Informatika merupakan salah satu program studi yang ada di Universitas Muhammadiyah Malang. Program studi Teknik Informatika memiliki bagian civitas akademika yaitu staff administrasi. Masalah yang sering dihadapi staff administrasi jurusan Teknik Informatika adalah menjawab pertanyaan mahasiswa terkait keberadaan dosen. Hal seperti itu dapat mengganggu kinerja dan fokus kerja staff administrasi. Untuk mengatasi masalah tersebut, staff administrasi jurusan Teknik Informatika memerlukan sebuah sistem informasi keberadaan dosen. Sebelum membangun sebuah sistem informasi dibutuhkan sebuah perancangan prototype interface web. Penelitian ini menggunakan perancangan User Experience Design Process untuk meningkatkan kepuasan pengguna dalam berinteraksi dengan produk dan pada tahap akhir dilalukan evaluasi Usability Testing untuk uji kebergunaan produk. Hasil dari penelitian ini berupa rancangan prototype interface sistem informasi keberadaan dosen dan hasil dari evaluasi pengolahan data kuesioner terdapat beberapa pertanyaan yang memiliki nilai skala rendah, oleh karena itu diberikan rekomendasi perbaikan interface dari prototype tersebut untuk pengembangan selanjutnya. Secara uтum perbaikan interface terletak pada bagian informasi status keberadaan dosen, simbol icon pada interface web dan desain warna web pada prototype interface. Saran rekomendasi perbaikan dapat digunakan dalam pengembangan lebih lanjut prototype interface ke tahap implementasi coding.
\end{abstract}

Kata kunci: Prototype, Sistem Informasi Keberadaan Dosen, Usability Testing , User Experience Design Process

\section{Pendahuluan}

Universitas Muhammadiyah Malang (UMM) merupakan salah satu lembaga pendidikan tinggi yang selalu mengikuti perkembangan teknologi informasi dan memanfaatkan teknologi dengan baik. UMM selalu berusaha memberikan fasilitas dan pelayanan kepada seluruh civitas akademik dengan menyediakan berbagai macam sistem informasi akademik yang memanfaatkan teknologi internet [1]. Salah satu pendukung produktivitas kinerja sebuah program studi adalah civitas akademikanya. Bagian dari civitas akademika yang berperan dalam sebuah kinerja program studi yaitu staff administrasi.

Berdasarkan hasil observasi dan wawancara dengan staff administrasi jurusan Teknik Informatika yaitu pegawai dan beberapa tenaga kerja partime, permasalahan sepele yang sering dihadapi staff administrasi adalah menjawab pertanyaan mahasiswa terkait keberadaan dosen. Masalah tersebut secara tidak langsung dapat mengganggu fokus bekerja staff administrasi. Fokus bekerja penting dalam dunia pekerjaan sebagai penentu hasil kerja [2]. Seiring dengan permasalahan tersebut, diperlukan sebuah Sistem Informasi Keberadaan Dosen. Sistem Informasi Keberadaan Dosen merupakan sebuah sistem informasi berbasis web yang dirancang dengan tujuan untuk mengatasi masalah yang telah dibahas sebelumnya. Dalam membangun sebuah sistem informasi dibutuhkan prototype interface web. Menurut Laudon [3], prototype merupakan model awal dari sistem yang sudah dapat berfungsi. [4].

Rancang Bangun Prototype Sistem Informasi Keberadaan Dosen dalam penelitian ini di desain menggunakan User Experience. User Experience menilai seberapa kepuasan dan kenyamanan seseorang terhadap sebuah produk, sistem, dan jasa Dalam penggunaan suatu interface, terkadang user mengalami kesulitan selama proses interaksinya. Menurut laporan dari IEEE menunjukkan sekitar $50 \%$ waktu pengerjaan ulang sistem dapat dihindari dengan dilakukan pengujian terhadap prototype pada tahap awal desain [4]. Pengujian interface yang digunakan dalam penelitian ini adalah pengujian kebergunaan (usability testing) dengan melibatkan user. Pengujian dilakukan untuk mengetahui seberapa besar kemudahan interface dapat digunakan oleh user sehingga dapat diterima di lingkungan operasional. [5]. 
Metode penelitian yang digunakan pada penelitian ini adalah sebagai berikut :

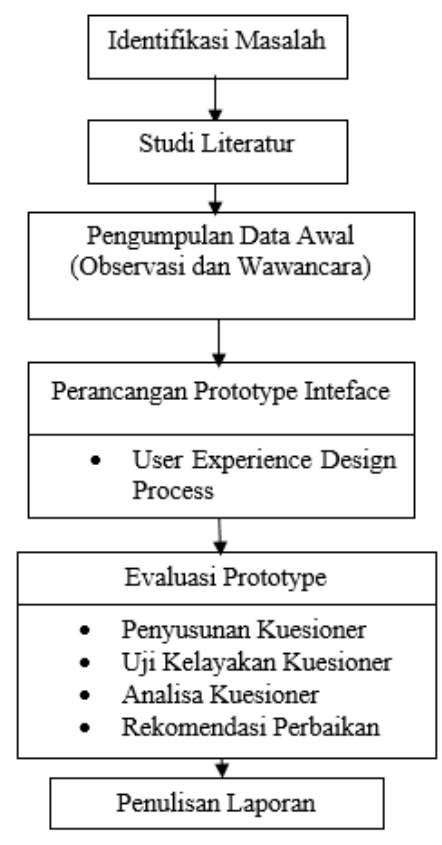

Gambar 1.Metodologi Penelitian

\section{a. Identifikasi Masalah}

Identifikasi masalah digunakan untuk mengetahui apa yang akan dilakukan pada penelitian ini, seperti yang sudah dibahas pada bab sebelumnya. Melihat manfaat yang diperoleh dengan adanya perancangan sistem informasi keberadaan dosen, maka sudah selayaknya suatu instansi membangun prototype sistem informasi untuk tahap awal. Dan masih jarang dilakukan evaluasi terhadap prototype sistem informasi yang sudah dirancang. Evaluasi dilakukan untuk mengetahui bagaimana kegunaan model prototype tersebut di lingkungan Teknik Informatika. Evaluasi ini akan sangat bermanfaat bagi pengembang, sebagai salah satu dasar pengembangan sistem informasi. Selain itu, hasil evaluasi prototype dari pengguna juga berpengaruh pada sejauh mana interface diterima oleh penggunanya.

\section{b. Studi Literatur}

Studi Literatur dilakukan untuk mempelajari semua literatur yang berhubungan dengan penelitian yang dilakukan. Dengan dilakukannya studi literatur, peneliti dapat memahami segala hal yang berhubungan dengan Prototype, UI Design, UX Design Process, Usability Testing dan semua evaluasi terkait tentang Usability Testing serta dokumen lain yang berkaitan dengan penelitian.

\section{c. Pengumpulan Data Awal}

Dalam tahapan ini dilakukan pengumpulan data awal melalui observasi serta wawancara langsung di bagian staff administrasi Kantor Jurusan Teknik Informatika dengan pegawai dan tenaga kerja partime. Observasi dan wawancara dilakukan sebanyak 2 kali dalam dua bulan, dari wawancara tersebut dapat diketahui bahwa Kantor Jurusan Teknik Informatika Universitas Muhammadiyah Malang memerlukan sebuah sistem informasi yang mampu meringankan pekerjaan staff administrasi. Dari wawancara yang telah dilakukan dapat diketahui, walaupun penelitian ini lingkupnya kecil namun memberikan manfaat sendiri bagi Jurusan Teknik Informatika.

\section{d. Perancangan Prototype Interface}

Pada tahap ini akan dilakukan perancangan prototype interface dengan metode User Experience Design Process.

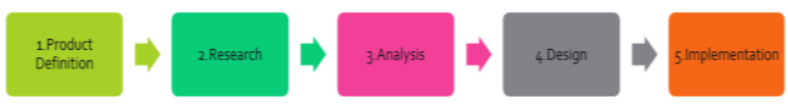

Gambar 2. Tahapan proses pada User Experience Design Process [6]

- Product Definition

Produk yang akan dibuat adalah sebuah prototype Sistem Informasi Keberadaan Dosen, yang bertujuan untuk mengetahui informasi keberadaan dosen Teknik Informatika tanpa harus bertanya kepada staff administrasi. untuk mendapatkan detail kebutuhan ada beberapa tahap yang dilakukan adalah memahami keadaan lingkungan sekitar jurusan Teknik Informatika, mengumpulkan ide dari beberapa user dan menyatukan ide - ide dari user.

- Research

Tahapan Research adalah melakukan user research untuk mengetahui tanggapan dari calon user. Tahapan dasar dalam melakukan user research adalah merencanakan pengguna yaitu Dosen, Staff Administrasi, Mahasiswa dan mengadakan penelitian seperti wawancara atau survei.

- Analysis

Dilakukan analisis terhadap apa yang sudah didapatkan pada tahap research, terutama terhadap user research. Dari hasil wawancara, survei, atau teknik pengambilan data lainnya akan digunakan untuk menentukan persona. Persona adalah dokumen yang mendeskripsikan target user, dapat dikatakan sebagai representasi dari responden dalam pengumpulan data. Persona dapat membantu untuk fokus terhadap user agar lebih spesifik. Dari proses wawancara atau survei bisa didapatkan biografi dari target user, kebutuhan, masalah, dan apa yang diinginkan user.

- Design

Hasil dari desain ini akan diujikan kepada calon user bagaimana tanggapan mereka terhadap desain yang. Sebuah prototype adalah versi draft atau produk 
yang akan membawa representasi sedekat mungkin dengan user, baik dari website dan user interfacenya sebelum coding dimulai. Dengan membangun sebuah prototype dari desain sebelum pengembangan lebih lanjut, penulis membuat sejumlah penghematan, baik dari segi biaya dan waktu.

- Implementation

Pada tahap implementasi Design adalah dilakukan Live Release terhadap produk prototype yang telah dibuat untuk diujikan kepada calon pengguna atau user [6].

\section{e. Evaluasi Prototype}

Pada tahap ini akan dilakukan evaluasi pada prototype interface menggunakan Usability Testing dengan metode kuesioner.

- Penyusunan Kuesioner

Tahapan selanjutnya dalam penelitian ini adalah penyusunan kuesioner. Penyusunan kuesioner dilakukan dengan mengacu pada indikator yang diperoleh dari tahapan studi literatur. Kuesioner yang digunakan dalam penelitian ini menggunakan skala likert. Kelebihan dari skala likert sendiri memperlihatkan item yang dinyatakan dalam beberapa responsi alternatif dan memberikan keterangan yang lebih nyata tentang pendapat atau sikap responden [7].

Dalam suatu usability testing, pada awalnya masing - masing responden akan diberikan beberapa task atau tugas yang harus dilakukan terlebih dahulu terhadap prototype yang akan diuji, Setelah Task diberikan pada responden, langkah selanjutnya yang dilakukan adalah dengan cara membagikan kuesioner untuk mendapatkan penilaian dari responden untuk mengetahui seberapa besar model prototype ini dipahami, diingat, dan lain - lain. Kuesioner yang diberikan terdiri dari 10 pertanyaan, dan dari 10 pertanyaan tersebut telah cukup untuk menunjukkan nilai aspek - aspek usability.

Dari tiap - tiap pertanyaan kuesioner ini nantinya bertujuan untuk menunjukkan tingkat Usability menurut penerimaan User. User yang akan mengisi kuesioner tersebut adalah Mahasiswa, Dosen dan Staff Administrasi. Masing - masing user akan diberikan kuesioner dengan pertanyaan yang berbeda namun memiliki tujuan yang sama [5].

- Uji Kelayakan Kuesioner

Tujuan dilakukannya tahap ini adalah untuk memperoleh data yang nantinya akan digunakan untuk Uji Validitas dan Uji Reliabilitas. Uji validitas dan uji reliabilitas dilakukan untuk mengetahui kestabilan jawaban responden dan mengetahui apakah item pertanyaan yang diajukan valid dan reliable [8].

- Analisa Hasil Kuesioner dan Rekomendasi Perbaikan

Analisa Hasil Kuesioner Usability testing yang dilakukan ini adalah sebagai berikut. User tes Usability yang digunakan adalah mahasiswa, dosen dan staff administrasi jurusan Teknik Infomatika UMM karena prototype yang dibuat hanya untuk sistem informasi di jurusan Teknik Informatik. Jumlah User yang digunakan adalah sebanyak 35 orang yang terdiri dari 25 orang Mahasiswa, 7 orang Dosen, dan 3 Orang Staff Administrasi. Nilai 35 dipilih berdasarkan dasar literatur yang menyampaikan bahwa jumlah User tes usability tidak perlu terlalu banyak jumlahnya. Seperti telah dijelaskan di awal, bahwa metode usability testing yang digunakan dalam penelitian ini adalah metode Kuisioner. Jumlah 35 orang ini dipilih sesuai dengan penelitian yang pernah dilakukan sebelumnya yang mengatakan bahwa responden Usability Testing tidak boleh terlalu banyak [9]. Berdasarkan hasil dari kuesioner yang akan dihitung menggunakan Microsoft Excel nanti, maka akan menghasilkan rekomendasi perbaikan prototype interface Sistem Informasi Keberadaan Dosen untuk pengembangan yang lebih lanjut.

\section{f. Penulisan Laporan}

Penulisan laporan adalah tahapan akhir dari penelitian ini. Pada tahap ini di uraikan hasil rancangan prototype dan evaluasi prototype Sistem Informasi Keberadaan Dosen menggunakan UX Design Process dan Usability Testing. Pada tahap ini juga akan di uraikan dokumen rekomendasi perbaikan interface untuk prototype Sistem Informasi Keberadaan Dosen jurusan Teknik Informatika.

\section{Pembahasan}

\subsection{Perancangan Prototype Interface}

Pada tahapan ini dilakukan proses perancangan prototype interface sesuai dengan kebutuhan yang telah disampaikan oleh user melalui kuisioner yang telah disebarkan. Berikut ini adalah langkah - langkah membuat rancangan interface yang dilakukan :

\section{- Menentukan User Persona}

Persona merupakan dokumen paling penting yang dibuat untuk menganalisis pengguna. Persona adalah pondasi untuk dokumentasi pengguna, yang memperluas personas untuk wawasan yang lebih mendalam [6].

1. Nama-Menggunakan nama pengguna

2. Demografi - referensi untuk kelompok- kelompok dasar yang ditargetkan.

3. Kepribadian - mencakup beberapa sifat

4. Teknologi - menunjukkan tingkat kerumitan untuk membuat sistem, atau mungkin berapa banyak penjelasan yang diperlukan untuk fungsi tertentu. 
5. Tujuan (Motivasi) - dapat dibagi menjadi harapan pengguna untuk mencapai dengan produk, serta tujuan produk.

6. Background - adalah membangun karakter persona

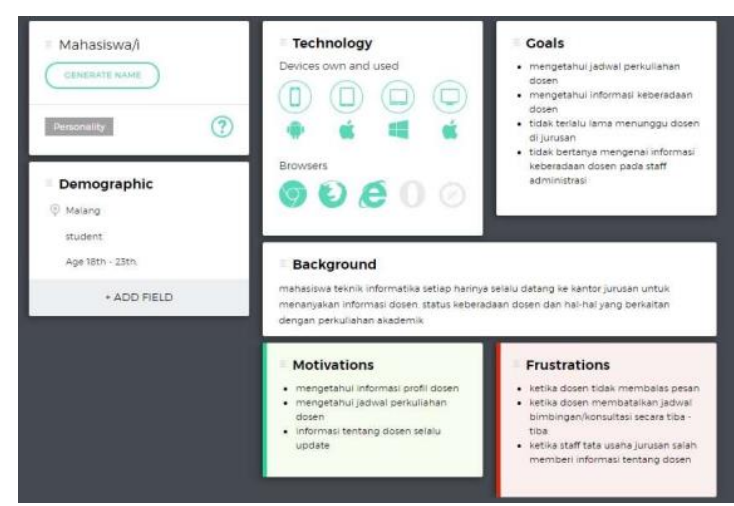

Gambar 3. Contoh User Persona Mahasiswa

- Membuat CJM (Costumer Journey Maps)

Costumer journey maps yang menggambarkan hubungan serta interaksi antara pelanggan dengan organisasi. Untuk setiap langkah, peta perjalanan pelanggan membahas keadaan pikiran pengguna di area-area ini [6]:

1. Goals (Sasaran) - Apa yang ingin mereka capai pada langkah ini?

2. Expectations (Harapan) - Bagaimana mereka berpikir langkah ini akan berjalan? Di luar pengaruh dan produk pesaing memiliki dampak besar pada ini.

3. Process (Proses) - Bagaimana mereka berharap untuk mencapai tujuan mereka? Melihat perbedaan antara proses yang mereka pilih dan yang terbaik proses.

4. Experience (Pengalaman) - Jika pengguna harus menilai tahap ini, apa akankah mereka katakan?

5. Problem - Apa yang disukai pengguna tentang tahap ini?

6. Ideas - Apa yang tidak disukai pengguna tentang tahap ini

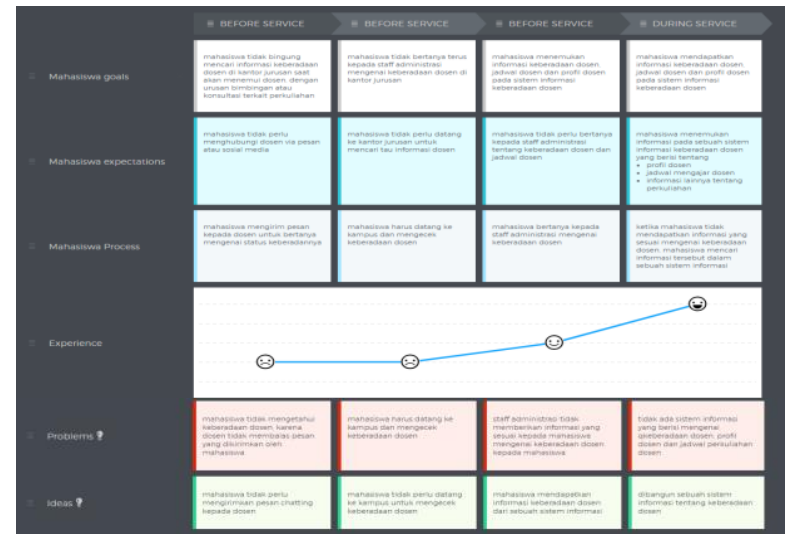

Gambar 4. Contoh Costumer Journey Maps Mahasiswa
- Perancangan Interface

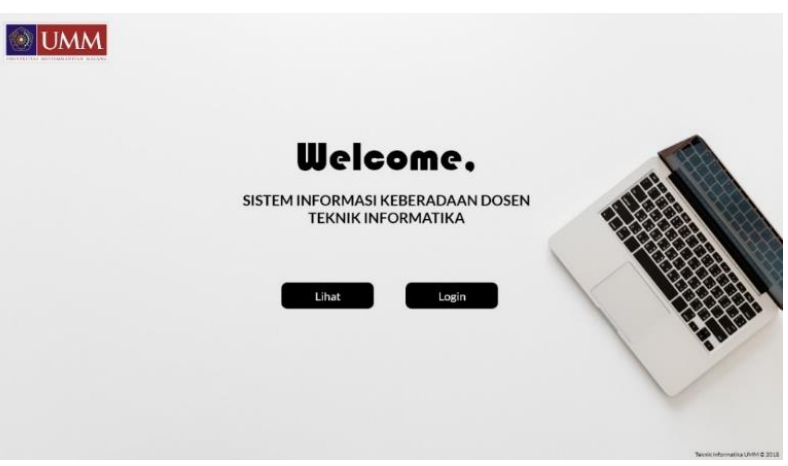

Gambar 5. Contoh Tampilan Menu Utama pada Web

Tampilan Menu Utama adalah tampilan yang pertama muncul ketika user membuka Sistem Informasi Keberadaan Dosen melalui website. Terdapat 2 menu utama di tampilan ini, yaitu menu Lihat dan menu Login. Untuk tampilan Menu Utama dapat dilihat pada Gambar 3 .

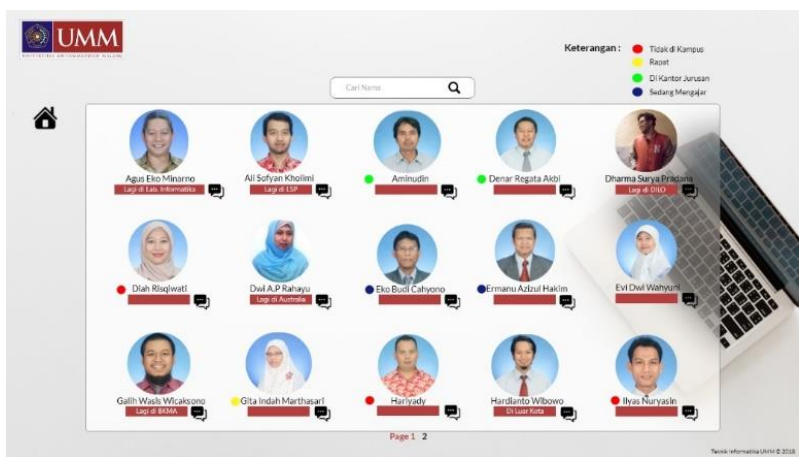

\section{Gambar 6. Contoh Tampilan Menu Utama layar}

Pada tampilan menu utama layar televisi jurusan, user tidak perlu login untuk melihat daftar nama - nama dosen berserta status keberadaannya. Halaman ini dapat ditampilkan pada layar televisi di depan kantor jurusan Teknik Informatika. Setiap 30 detik sekali layar akan berganti ke halaman selanjutnya halaman yang menampilkan status keberadaan dosen yang sama. halaman ini juga dapat diakses online pada website setelah menu utama tanpa login. Dapat dilihat pada gambar 6.

\subsection{Evaluasi Prototype Interface}

Dalam penelitian ini, peneliti menggunakan kuesioner model Nielsen sebagai parameter dalam pengukuran usability. Kuesioner model Nielsen terdiri dari lima komponen yaitu learnability (mudah dipelajari), efficiency (efisiensi), memorability (mudah diingat), errors (kesalahan) dan satisfaction (kepuasan). Pengukuran dilakukan dengan membagikan kuesioner kepada 35 responden, dengan objek prototype interface sistem informasi keberadaan dosen. Dari penelitian ini, 
responden yang berhak menjawab kuesioner adalah dosen, staff administrasi dan mahasiswa angkatan 2014 yang ada di lingkungan Teknik Informatika Universitas Muhammadiyah Malang.

Sebelum kuesioner penelitian dibagikan kepada responden, kuesioner tersebut harus melalui uji kelayakan kuesioner terlebih dahulu. Uji kelayakan kuesioner atau pengujian isi instrumen penelitian dilakukan untuk menguji apakah kuesioner yang akan digunakan memenuhi syarat baik atau tidak. Instrumen penelitian dapat dikatakan baik apabila telah memenuhi syarat dari nilai-nilai uji validitas dan uji realibilitas. Berikut ini adalah kuisioner yang akan disebarkan kepada responden :

\begin{tabular}{|c|c|c|c|c|c|c|}
\hline \multirow{2}{*}{ No } & \multirow{2}{*}{ Pertanyaan } & \multicolumn{5}{|c|}{ Skala } \\
\hline & & STS & TS & $\mathbf{N}$ & $\mathbf{S}$ & SS \\
\hline 1 & $\begin{array}{l}\text { Apakah website dapat } \\
\text { dikenali dari interface } \\
\text { awal? }\end{array}$ & & & & & \\
\hline 2 & $\begin{array}{l}\text { Apakah anda dapat } \\
\text { menemukan form login } \\
\text { dengan mudah? }\end{array}$ & & & & & \\
\hline 3 & $\begin{array}{l}\text { Apakah informasi dosen } \\
\text { dapat anda dapatkan } \\
\text { dengan mudah? }\end{array}$ & & & & & \\
\hline 4 & $\begin{array}{ll}\text { Apakah anda } & \text { dapat } \\
\text { menemukan } & \text { status } \\
\text { keberadaan } & \text { dosen } \\
\text { dengan mudah? } & \\
\end{array}$ & & & & & \\
\hline 5 & $\begin{array}{l}\text { Apakah anda dapat } \\
\text { menemukan nama - } \\
\text { nama dosen dengan } \\
\text { mudah? }\end{array}$ & & & & & \\
\hline 6 & $\begin{array}{l}\text { Apakah huruf yang ada } \\
\text { mudah dibaca? }\end{array}$ & & & & & \\
\hline 7 & $\begin{array}{l}\text { Apakah simbol mudah } \\
\text { dipahami? }\end{array}$ & & & & & \\
\hline 8 & $\begin{array}{l}\text { Apakah desain warna } \\
\text { web ini nyaman dilihat } \\
\text { ? }\end{array}$ & & & & & \\
\hline 9 & Lakukan Log Out & & & & & \\
\hline 10 & $\begin{array}{lr}\text { Setelah } & \text { Melakukan } \\
\text { Logout, apakah mudah } \\
\text { melakukan } \\
\text { kembali? }\end{array}$ & & & & & \\
\hline
\end{tabular}

\section{A. Uji Kelayakan Kuesioner}

- Uji Validitas

Pada kuesioner penelitian telah dilakukan uji validitas pada 10 pertanyaan yang ditentukan berdasarkan kuesioner Usability Testing. peneliti menggunakan 5\% dimana nilai $\mathrm{r}$ tabel sebagai acuan sebesar 0,361. Dari hasil uji validitas yang dilakukan dengan bantuan SPSS ini didapatkan hasil bahwa dari 10 atribut atau pernyataan yang ada, semua mendapatkan hasil yang valid. Hal ini diketahui dari hasil perhitungan $r$ hitung yang dilakukan nilainya lebih besar dari nilai $r$ tabel.

- Uji Reliabilitas

Pada pengujian ini didapatkan hasil nilai sebesar 0,809 . Nilai-nila tersebut kemudian dibandingnya dengan $r$ tabel dengan $\mathrm{n}=30$ dengan signifikasi $5 \%$, nilai $r$ tabel sebesar 0,361. Maka dapat disimpulkan bahwa nilai lebih besar daripada nilai $r$ tabel yang artinya semua pernyataan pada kuesioner sudah reliable dan terpercaya sebagai alat ukut penelitian.

\section{B. Analisa Hasil Kusioner}

Setelah dilakukan penyebaran kuesioner yang diberikan pada responden, maka selanjutnya dilakukan rekap terhadap hasil kuesioner yang telah disebar. Hasil dari Usability testing yang dilakukan terhadap 35 responden yang menggambarkan penyebaran jawaban dari masing - masing pertanyaan yang diberikan dalam kuesioner usability testing.

\section{Rekomendasi Perbaikan}

Setelah pengolahan data kuesioner yang dilakukan oleh penulis. Penulis memberikan rekomendasi perbaikan terhadap prototype yang telah dirancang. Rekomendasi yang diberikan berdasarkan dari beberapa pertanyaan yang memiliki nilai perhitungan terendah. Terdapat tiga pertanyaan yang memiliki nilai skala terendah yaitu pertanyaan nomer 3 mengenai informasi status keberadaan dosen, pertanyaan nomer 7 mengenai simbol pada web prototype dan pertanyaan nomer 8 apakah user nyaman desain warna web prototype yang dirancang.

Pada pertanyaan nomer 3 sebaiknya informasi keberadaan dosen yang ada pada interface tata letaknya lebih diatur lagi dan jenis huruf yang digunakan pada tulisan status diganti atau diperbesar lagi ukurannya, agar user dapat melihat jelas informasi tersebut. Untuk pertanyaan nomer 7 sebaiknya simbol icon interface pada prototype agar lebih diperbesar juga ukurannya, atau mungkin simbol dapat diganti dengan pilihan simbol yang lain. Untuk pertanyaan nomer 8 yaitu warna desain web pada prototype sebaiknya diberikan warna yang menarik pada website menimbulkan kesan positif, manfaat dan kepuasan oleh pengguna ketika mengakses terhadap sebuah situs website. Untuk rekomendasi perbaikan pada pertanyaan nomer 3, 7 dan 8 sebaiknya menggunakan penekanan atau Emphasis. Emphasis dimaksudkan untuk menarik perhatian pembaca atau orang yang melihat desain website tersebut, penekanan disitilahkan juga 
sebagai COI (center of interest). Pada website dapat diterapkan dengan cara pembuatan ukuran font yang cukup mencolok, serta pembuatan kontras pada tekstur, warna, garis, ruang, dan pada bentuk atau motif [9].

\section{Kesimpulan}

Kesimpulan yang dapat diambil dari penelitian ini antara lain sebagai berikut :

1. Prototype yang dirancang telah menggunakan metode UX Design Process yang terdiri dari langkah - langkah berikut, definisi produk yang dibuat, meneliti lingkungan sekitar dengan observasi dan wawancara, analisis kebutuhan dari hasil wawancara dan observasi, merancang prototype dan yang terakhir menguji prototype tersebut. Prototype yang dirancang menggunakan tools Adobe XD.

2. Evaluasi Usability Testing yang dilakukan menggunakan metode kuesioner. Penyebaran kuesioner diberikan kepada 35 responden, dengan syarat harus dari lingkungan jurusan Teknik Informatika Universitas Muhammadiyah Malang. Setelah data berupa kuisioner terisi dan terkumpul, maka akan dilakukan tahapan pengolahan data.

Saran dari penelitian ini yang dapat digunakan sebagai acuan untuk penelitian selanjutnya adalah :

1. Penelitian selanjutnya dapat melanjutkan prototype Sistem Informasi Keberadaan Dosen ke tahap Implementasi Coding.

2. Prototype Sistem Informasi Keberadaan Dosen dapat dikembangkan menjadi versi mobile

3. Perancangan prototype interface dapat dilakukan dengan metode penelitian lain seperti User Experience lainnya seperti UCD (User Centered Design), Walkthrough, 3E (Expressing Experiences and Emotions).

4. Evaluasi interface prototype dapat dilakukan dengan metode penelitian lainnya seperti User Experience Questionnare atau Heuristik Evaluation.

\section{DAFTAR PUSTAKA}

Kusuma, W. A., Noviasari, V., \& Marthasari, G. I. (2016). Analisis Usability dalam User Experience pada Sistem KRS- Online UMM menggunakan USE Questionnaire. Jnteti, 5(4), 294-301.

Kenapa Fokus Dalam Bekerja itu Penting (http://bkpp.kaboki.go.id/2017/03/30/kenapa-fokusdalam-bekerja-itu-penting/ diakses tanggal 6 Februari 2018)

Laudon, Kenneth C, Jane P. Laudon. 2008. Sistem Informasi Manajemen Edisi 10. Salemba Empat, Jakarta.

Usability Testing With Prototypes (https://usabilitygeek.com/usability-testingprototypes// diakses tanggal 28 Februari 2018)

Wignjosoebroto, S., Sudiarno, A., \& Harenda, D. (2011). Perancangan Interface Prototype Web Berdasarkan Pada Aspek Usability ( Studi Kasus : Laboratorium Ergonomi dan Perancangan Sistem Kerja Teknik Industri ITS ), 1-14. Retrieved from http://digilib.its.ac.id/public/ITS-Undergraduate8877-2504100030-Paper.pdf

Cao, Jerry, Ben Gremillion, Kamil Ziebak, and Matt Ellis. 2015. "UX Design Process Best Practices." UXPin 111.

Moh. Nasir, Ph.D, 1999, Metode Penelitian, Ghalia Indonesia

Sugiyono, P. D. (2006). Statistik Untuk Penelitian. CV ALFABETA Bandung, 10(1), 403. 21

Battleson, B., Booth, A., \& Weintrop, J. (2001). Usability testing of an academic library Web site: a case study. The Journal of Academic Librarianship, 27(3), 188-198. https://doi.org/10.1016/S00991333(01)00180-X

Kuswanto, H. (2006). Analisis Prinsip Layout and Composition pada Web Design Perusahaan PT . Bank Rakyat Indonesia, Tbk dan PT . FIF Group berdasarkan Buku " The Principle of Beautifull Website Design ( 2nd Edition ) By Jason Beaird ." 